\title{
Participants' perception of pharmaceutical clinical research: a cross-sectional controlled study
}

\author{
This article was published in the following Dove Press journal: \\ Patient Preference and Adherence \\ 29 April 2016 \\ Number of times this article has been viewed
}

\author{
Gerardo González-Saldivar' \\ René Rodríguez-Gutiérrez ${ }^{2}$ \\ José Luis Viramontes- \\ Madrid $^{3}$ \\ Alejandro Salcido- \\ Montenegro ${ }^{2}$ \\ Kevin Erick Gabriel Carlos- \\ Reyna $^{2}$ \\ Andrés Marcelo Treviño- \\ Alvarez $^{2}$ \\ Neri Alejandro Álvarez- \\ Villalobos ${ }^{4}$ \\ José Gerardo González- \\ González ${ }^{2}$ \\ 'Ophthalmology Department, \\ ${ }^{2}$ Endocrinology Division, Hospital \\ Universitario “Dr. José E. González", \\ Facultad de Medicina, Universidad \\ Autónoma de Nuevo León, Monterrey, \\ Nuevo León, ${ }^{3}$ Instituto Nacional de \\ Salud Pública, Cuernavaca, Morelos, \\ ${ }^{4}$ Medical Statistics Department, \\ Hospital Universitario "Dr. José E. \\ González", Facultad de Medicina, \\ Universidad Autónoma de Nuevo \\ León, Monterrey, Nuevo León, Mexico
}

Correspondence: José Gerardo González-González

Endocrinology Division, Hospital Universitario "Dr. José E. González," Facultad de Medicina, Universidad Autónoma de Nuevo León, Ave Madero y Gonzalitos s/n, Col Mitras Centro, CP 64460 Monterrey, Nuevo León, Mexico $\mathrm{Tel} / \mathrm{fax}+528183483220$

Email jgerardo@meduanl.com
Background: There is scarce scientific information assessing participants' perception of pharmaceutical research in developed and developing countries concerning the risks, safety, and purpose of clinical trials.

Methods: To assess the perception that 604 trial participants (cases) and 604 nonparticipants (controls) of pharmaceutical clinical trials have about pharmaceutical clinical research, we surveyed participants with one of four chronic diseases from 12 research sites throughout Mexico.

Results: Participation in clinical trials positively influences the perception of pharmaceutical clinical research. More cases (65.4\%) than controls (50.7\%) perceived that the main purpose of pharmaceutical research is to cure more diseases and to do so more effectively. In addition, more cases considered that there are significant benefits when participating in a research study, such as excellent medical care and extra free services, with this being the most important motivation to participate for both groups (cases $52 \%$, controls $54.5 \%$ ). We also found a sense of trust in their physicians to deal with adverse events, and the perception that clinical research is a benefit to their health, rather than a risk. More controls believed that clinical trial participants' health is put at risk ( $57 \%$ vs $33.3 \%)$. More cases $(99.2 \%)$ than controls $(77.5 \%)$ would recommend participating in a clinical trial, and $90 \%$ of cases would enroll in a clinical trial again.

Conclusion: Participation in clinical trials positively influences the perception that participants have about pharmaceutical clinical research when compared to nonparticipants. This information needs to be conveyed to clinicians, public health authorities, and general population to overcome misconceptions.

Keywords: perceptions, clinical trials, chronic disorders, participants' perception, pharmaceutical industry, developing countries

\section{Introduction}

During the past 3 decades, pharmaceutical clinical trials have intensively increased worldwide, significantly expanding into developing countries. ${ }^{1-3}$ In the last 5 years, registration of research conducted in Latin America in the ClinicalTrials.gov registry has increased from 4,499 to $11,100 .^{4}$

As a consequence of ethical misconduct by some researchers, both the international clinical research regulations and the concern of providing appropriate protection to clinical research participants have grown intensively.,6 Unfortunately, a lack of audits or inspections in many clinical research sites all over the world is evident. ${ }^{1,3,7}$ Certification by well-known associations focusing on the protection of participants is now highly recommended by public health agencies. ${ }^{8}$ Despite these efforts to ensure ethical behavior regarding participant protection in clinical research, there is still very limited information regarding the participants' perception of the risks, safety, and 
purpose of clinical trials. ${ }^{9-13}$ Recent efforts have been made to approach clinical research participants and assess their perception and experiences with tools such as the Research Participant Perception Survey and organizations such as the Patient-Centered Outcomes Research Institute. ${ }^{11,13-16}$ Nevertheless, these efforts still focus on developed countries and clinical research sites with certified clinical practice excellence. Comparing the perceptions of participants from the USA and the rural and urban People's Republic of China yielded different reasons and concerns about participating in clinical research. ${ }^{17}$ A scientific examination of this issue may generate critical feedback that could improve the execution of clinical trials.

We conducted a cross-sectional, controlled, multicenter survey in various academic and nonacademic pharmaceutical clinical research sites. The primary end point was to assess participant's perception (ie, regard and understanding) of clinical research trials in a large population with one of four highly prevalent chronic diseases: type 2 diabetes, hypertension, chronic obstructive pulmonary disease, and rheumatoid arthritis. The secondary end point was to compare their perceptions by sex, age, and disease to determine whether they were influenced by the inherent characteristics of the participant categories classified by these variables.

\section{Methods}

\section{Study participants}

Ethics approval was obtained from Comité de Ética en Investigación de la Facultad de Medicina y Hospital Universitario de la Universidad Autónoma de Nuevo León. From September 2013 to March 2014, research sites consecutively enrolled patients who met all eligibility criteria. Cases were males and females, aged 18-80 years, who had lived in Mexico for at least 10 years, who had participated or were currently participating in Phase II or III pharmaceutical industry-funded clinical trials, and who had attended at least their sixth visit. Trial participants (cases) were recruited in equally proportionate populations among each of the four chronic degenerative disorders evaluated (type 2 diabetes, hypertension, chronic obstructive pulmonary disease, and rheumatoid arthritis). In the eventuality of studied comorbidities, the disease of interest in their clinical trial determined the assignment into our study disease groups. These four chronic diseases were chosen because of their high prevalence and the high number of approved treatments already available and because they have a low short-term risk of death or serious complications. Cases were paired (correspondingly distributed by disease) with controls, who had never participated in, or been invited to participate in, a clinical trial and who had visited the primary care and specialty outpatient clinics for reasons other than trials. Recruitment took place in 12 clinical research sites throughout Mexico. All participants provided written informed consent and were able to complete the self-survey.

\section{Clinical research sites}

All the research sites had participated in pharmaceutical research (in $>45$ clinical trials), for at least 10 years, and had a professional pharmaceutical research team; nine out of the 12 sites had sections within their facilities designated for conducting clinical trials. All sites also provided primary care and specialty outpatient services to the general population.

\section{Study protocol}

Cases were invited to participate while attending their research study site and controls while at their specialty outpatient clinics. In all cases, a staff member, unrelated to the trial the patient was enrolled in, acquired the patient's demographic data and explained the survey. Any questions from participants were clarified by the research site staff in charge of the surveys. Once finished, the evaluator reviewed whether the survey was correctly completed. After completion, all surveys were sent back to a central site for data management.

\section{Procedures}

The survey was developed by two of the authors (JGGG and JLVM) with $>15$ years of experience in original and pharmaceutical clinical research, based on their experience in day-today clinical research activities. A two-phase prepilot study and a pilot study were performed to validate the survey. First, the original draft was tested in two focus groups, each with seven to eight participants ( $80 \%$ previously involved in a clinical research study). Then, two individual semistructured interviews were randomly chosen to be used in six out of the 12 sites (12 interviews in total). Key points mentioned by the participants in each stage were used to revise the questions and their order of appearance in the survey. After this, a final questionnaire was formulated and piloted in a total of 30 individuals who had the same eligibility criteria as the ones included in this study. Minor inconsistencies were found and taken into account to draft the survey used in this study (Supplementary material). All surveys were completed with paper and pencil.

One hundred surveys were sent to each research site: 50 for cases and 50 for controls. In all research sites, the staff member responsible for survey application received a careful explanation about the procedure and possible questions that 
could arise during the evaluation. We analyzed 17 multiplechoice questions: each with two to eight choices. Both cases and controls were surveyed with the same questions in addition to a unique question specifically designed for each group. Data presented in this article are a fraction of the whole survey, given that it assessed diverse subtopics regarding participants' perception of clinical research. This study focused on the general perception and motives for participation in pharmaceutical clinical research.

\section{Statistical analysis}

All results are reported as mean \pm SD unless otherwise stated. A $P$-value $\leq 0.05$ was statistically significant. Descriptive statistics were used for quantitative variables, measures of central tendency, and dispersion. In the case of qualitative variables, frequencies were obtained. In quantitative comparative data, we used an unpaired Student's $t$-test. The response differences between groups were studied using Pearson's $\chi^{2}$ test or Fisher's exact test for $2 \times 2$ tables. The statistical analysis was performed using IBM SPSS Statistics 20.0 (IBM Corporation, Armonk, NY, USA).

\section{Results}

\section{Study population}

Demographic and clinical characteristics of the study population are shown in Table 1. A total of 1,208 participants were included: 604 cases and an equal number of controls. All participants approached agreed to be included. Twothirds of the cases $(65.4 \%)$ were participating in pharmaceutical research for the first time. Cases were significantly older than controls $(54.8 \pm 13.9$ years vs $47.0 \pm 15.5$ years, $P<0.05)$. Two-thirds of cases and controls were female. More than one-third of the whole study population had at least 9 years of education, and $>75 \%$ had access to social or private health insurance.

\section{Perception of pharmaceutical clinical research}

The most and least common responses are shown in Table 2. Unless otherwise stated, statistical analysis by sex, age, and disease category was not different from the results found in the statistics as a whole group.

To cure more diseases and to do so more effectively were considered the main reasons for pharmaceutical companies to conduct clinical trials (cases 65.4\%; controls 50.7\%). More cases $(98.8 \%)$ than controls $(81.3 \%)$ believed that it is correct to perform research on humans. Controls considered trials as a business $(4.3 \%)$, more so than cases $(0.5 \%)$, and were more likely to believe that its risks outweigh the benefits (controls $12.1 \%$ vs cases $1.2 \%$ ).

More cases felt protected in case of a serious adverse event related to the experimental drugs (93.4\%) compared

Table I Demographic and clinical characteristics of the study population

\begin{tabular}{|c|c|c|c|c|c|c|c|c|c|c|}
\hline \multirow[t]{2}{*}{ Characteristic } & \multicolumn{2}{|c|}{ Study population } & \multicolumn{2}{|l|}{ DM2 } & \multicolumn{2}{|l|}{ COPD } & \multicolumn{2}{|l|}{ RA } & \multicolumn{2}{|l|}{ HT } \\
\hline & $\begin{array}{l}\text { Cases } \\
(n=604)\end{array}$ & $\begin{array}{l}\text { Controls } \\
(n=604)\end{array}$ & $\begin{array}{l}\text { Cases } \\
(n=15 I)\end{array}$ & $\begin{array}{l}\text { Controls } \\
(n=15 I)\end{array}$ & $\begin{array}{l}\text { Cases } \\
(n=15 I)\end{array}$ & $\begin{array}{l}\text { Controls } \\
(n=\mid 5 I)\end{array}$ & $\begin{array}{l}\text { Cases } \\
(n=15 I)\end{array}$ & $\begin{array}{l}\text { Controls } \\
(n=\mid 5 I)\end{array}$ & $\begin{array}{l}\text { Cases } \\
(n=15 I)\end{array}$ & $\begin{array}{l}\text { Controls } \\
(n=15 I)\end{array}$ \\
\hline Age, mean \pm SD (years) & $54.9 \pm 13.9$ & $47.1 \pm 15.5^{*}$ & $52.2 \pm 12.8$ & $46.6 \pm 15.7^{*}$ & $60.3 \pm 14.2$ & $53.1 \pm 16.7 *$ & $50.1 \pm 13.4$ & $41.6 \pm 15.3^{*}$ & $56.8 \pm 13.1$ & $47 \pm 12.1 *$ \\
\hline \multicolumn{11}{|l|}{ Age group, n (\%) } \\
\hline$<50$ years & $216(35.8)$ & $320(53.0)^{*}$ & $68(45.0)$ & $83(55.0)$ & $31(20.5)$ & $57(37.7)^{*}$ & $71(47.0)$ & $103(68.2)^{*}$ & $46(30.5)$ & $77(5 \mathrm{I} .0)^{*}$ \\
\hline$\geq 50$ years & $388(64.2)$ & $284(47.0)$ & $83(55.0)$ & $68(45.0)$ & $120(79.5)$ & $94(62.3)$ & $80(53.0)$ & $48(31.8)$ & 105 (69.5) & $74(49.0)$ \\
\hline \multicolumn{11}{|l|}{ Sex, n (\%) } \\
\hline Female & $377(62.4)$ & $394(65.2)$ & I0I (66.9) & $95(62.9)$ & $69(45.7)$ & $92(60.9)^{* *}$ & $126(83.4)$ & I I0 (72.8)** & $81(53.6)$ & $97(64.2)$ \\
\hline Male & $227(37.6)$ & $210(34.8)$ & $50(33.1)$ & $56(37.1)$ & $82(54.3)$ & $59(39.1)$ & $25(16.6)$ & $4 I(27.2)$ & $70(46.4)$ & $54(35.8)$ \\
\hline \multicolumn{11}{|l|}{ Years of education, n (\%) } \\
\hline$<9$ years & $363(60.1)$ & $34 I(56.5)$ & $90(59.6)$ & $82(54.3)$ & 89 (58.9) & $76(50.3)$ & $90(59.6)$ & $85(56.3)$ & $94(62.3)$ & $98(64.9)$ \\
\hline$\geq 9$ years & $24 I(39.9)$ & $263(43.5)$ & $61(40.4)$ & $69(45.7)$ & $62(4 I .1)$ & $75(49.7)$ & $61(40.4)$ & $66(43.7)$ & $57(37.7)$ & $53(35.1)$ \\
\hline \multicolumn{11}{|l|}{ Health care, n (\%) } \\
\hline Yes & $476(78.8)$ & $453(75)$ & $122(80.8)$ & I I8 (78.1) & $116(76.8)$ & $121(80.1)$ & $112(74.2)$ & $116(76.8)$ & $126(83.4)$ & $98(64.9)^{*}$ \\
\hline No & $128(21.2)$ & $|5|(25)$ & $29(19.2)$ & $33(21.9)$ & $35(23.2)$ & $30(19.9)$ & $39(25.8)$ & $35(23.2)$ & $25(16.6)$ & $53(35.1)$ \\
\hline \multicolumn{11}{|c|}{ Previous clinical trial participation (case group only), n (\%) } \\
\hline One & $395(65.4)$ & & 89 (58.9) & & 89 (58.9) & & 119 (78.8) & & $98(64.9)$ & \\
\hline Two to three & $196(32.5)$ & & $60(39.7)$ & & $56(37.1)$ & & $28(18.5)$ & & $52(34.4)$ & \\
\hline Three to six & $10(1.7)$ & & $2(1.3)$ & & $5(3.3)$ & & $2(1.3)$ & & I (0.7) & \\
\hline More than six & $3(0.5)$ & & $0(0)$ & & $\mathrm{I}(0.7)$ & & $2(1.3)$ & & $0(0)$ & \\
\hline
\end{tabular}

Notes: $* P \leq 0.001 ; * * P \leq 0.05$

Abbreviations: COPD, chronic obstructive pulmonary disease; DM2, diabetes mellitus type 2; HT, hypertension; RA, rheumatoid arthritis. 
Table 2 Comparison of the two most and least common answers between cases and controls

\begin{tabular}{|c|c|c|c|}
\hline Questions and answers & \multirow{2}{*}{$\begin{array}{l}\text { Case group } \\
(n=604)\end{array}$} & \multirow{2}{*}{$\begin{array}{l}\text { Control group } \\
(\mathrm{n}=604)\end{array}$} & \multirow[t]{2}{*}{ P-value } \\
\hline I. Why do pharmaceutical companies do research? & & & \\
\hline To cure more diseases and do so more effectively ${ }^{a}$ & $395(65.4)$ & $306(50.7)$ & $\leq 0.001$ \\
\hline To find out whether new medications will be more effective and secure ${ }^{a}$ & |3| (2I.7) & $145(24)$ & \\
\hline Because research of new drugs is a business ${ }^{b}$ & $3(0.5)$ & $26(4.3)$ & \\
\hline So physicians can have new medications ${ }^{b}$ & $14(2.3)$ & $12(2)$ & \\
\hline \multicolumn{4}{|l|}{ 2. Do you believe it is correct to perform research studies on humans? } \\
\hline Yes & $597(98.8)$ & $491(81.3)$ & $\leq 0.001$ \\
\hline No & $7(1.2)$ & $113(18.7)$ & \\
\hline 3. Why do you believe that performing research on humans is reasonable? & $\mathrm{n}=597$ & $n=491$ & \\
\hline It is a good and reasonable option for people who cannot afford treatment by themselves ${ }^{a}$ & $247(41.4)$ & $162(33)$ & $\leq 0.001$ \\
\hline It is reasonable as long as patients are closely monitored to identify the risks that could arise ${ }^{a}$ & $167(28)$ & $153(31.2)$ & \\
\hline It is reasonable only in the case of certain diseases such as cancer ${ }^{b}$ & $2(0.3)$ & $5(1)$ & \\
\hline 4. Why do you believe that performing research on humans is "not" reasonable? & $n=7$ & $\mathrm{n}=113$ & \\
\hline Because human beings must not be treated like "guinea pigs"a & $5(71.4)$ & $55(48.7)$ & 0.727 \\
\hline Because research is only conducted on people without other health care alternatives ${ }^{\mathrm{a}}$ & $0(0)$ & $13(11.5)$ & \\
\hline $\begin{array}{l}\text { Because in our country, medical researchers and the sites, where research is conducted, are not } \\
\text { under surveillance }{ }^{b}\end{array}$ & $0(0)$ & $13(11.5)$ & \\
\hline Because health is put at risk ${ }^{b}$ & $0(0)$ & $6(5.3)$ & \\
\hline \multicolumn{4}{|l|}{ 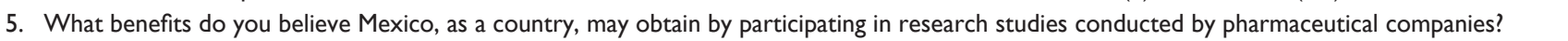 } \\
\hline To promote the development of clinical research centers and research physicians ${ }^{\mathrm{a}}$ & $360(59.6)$ & $370(61.3)$ & 0.011 \\
\hline To offer expensive high-quality medical health care but free of charge to participants ${ }^{\mathrm{a}}$ & $90(14.9)$ & $73(12.1)$ & \\
\hline To offer the participants medications not yet available to the general public ${ }^{b}$ & $73(12.1)$ & $73(12.1)$ & \\
\hline I do not believe there are any benefits ${ }^{\mathrm{b}}$ & $5(0.8)$ & $20(3.3)$ & \\
\hline \multicolumn{4}{|c|}{ 6. What benefits do you believe a patient may obtain by participating in a research study conducted by a pharmaceutical company? } \\
\hline $\begin{array}{l}\text { Participants receive free medical extra services besides the experimental drug such as education } \\
\text { about their disease, nutritional evaluation and guidelines, medical equipment (eg, glucometer), etc }{ }^{\mathrm{a}}\end{array}$ & $391(64.7)$ & $343(56.8)$ & $\leq 0.001$ \\
\hline Participants receive excellent medical care ${ }^{a}$ & $129(21.4)$ & $68(11.3)$ & \\
\hline In most cases, the benefits are minimal; instead, participants expose themselves to risks ${ }^{\mathrm{b}}$ & $7(1.2)$ & $34(5.6)$ & \\
\hline I do not believe there are any benefits ${ }^{b}$ & $0(0)$ & $30(5)$ & \\
\hline
\end{tabular}

7. In case of a serious adverse event related to the experimental drug that could lead to a complication or disability, do you believe that a study participant is protected?

Yes

\begin{tabular}{|c|c|c|}
\hline $564(93.4)$ & 416 (68.9) & $\leq 0.001$ \\
\hline $40(6.6)$ & I88 (3I.I) & \\
\hline$n=564$ & $n=416$ & \\
\hline $4 \mid 4(73.4)$ & 282 (67.8) & 0.037 \\
\hline I0I (I7.9) & $76(18.3)$ & \\
\hline $45(8)$ & 49 (II.8) & \\
\hline$n=40$ & $n=188$ & \\
\hline $16(40)$ & $74(39.4)$ & 0.167 \\
\hline $15(37.5)$ & $87(46.3 \%)$ & \\
\hline $3(7.5)$ & I7 (9) & \\
\hline 201 (33.3) & 344 (57) & $\leq 0.001$ \\
\hline 403 (66.7) & $260(43)$ & \\
\hline$n=201$ & $n=344$ & \\
\hline $69(34.3)$ & $83(24.1)$ & $\leq 0.001$ \\
\hline $58(28.9)$ & $73(2 \mid .2)$ & \\
\hline $9(4.5)$ & $56(16.3)$ & \\
\hline $8(4)$ & $5(1.5)$ & \\
\hline$n=403$ & $n=260$ & \\
\hline $213(52.9)$ & I3| (50.4) & $\leq 0.001$ \\
\hline $54(13.4)$ & $29(11.2)$ & \\
\hline
\end{tabular}


Table 2 (Continued)

\begin{tabular}{|c|c|c|c|}
\hline Questions and answers & $\begin{array}{l}\text { Case group } \\
(n=604)\end{array}$ & $\begin{array}{l}\text { Control group } \\
(n=604)\end{array}$ & P-value \\
\hline Because I am sure that the physician would not invite me to participate if there were any risks ${ }^{\mathrm{b}}$ & $18(4.5)$ & $44(16.9)$ & \\
\hline I simply do not believe there are risks involved ${ }^{b}$ & $12(3)$ & $6(2.3)$ & \\
\hline \multicolumn{4}{|c|}{$\begin{array}{l}\text { I3. Do you believe that the most important reason that motivates a person to participate in this type of studies is the fact that everything is free, } \\
\text { including medications? }\end{array}$} \\
\hline Yes & $314(52)$ & $329(54.5)$ & $\leq 0.001$ \\
\hline No & $248(4 I .1)$ & $177(29.3)$ & \\
\hline I do not know & $42(7)$ & $98(16.2)$ & \\
\hline \multicolumn{4}{|l|}{ 14. Would you recommend others to participate in a pharmaceutical clinical trial? } \\
\hline Yes & $599(99.2)$ & 468 (77.5) & $\leq 0.001$ \\
\hline No & $5(0.8)$ & 136 (22.5) & \\
\hline \multicolumn{4}{|c|}{ I5. Would you recommend a person without financial limitations to get clinical care to participate in a pharmaceutical clinical trial? } \\
\hline Yes & 497 (82.3) & 361 (59.8) & $\leq 0.001$ \\
\hline No & $107(17.7)$ & $243(40.2)$ & \\
\hline \multicolumn{4}{|l|}{ 16. Would you participate in a drug research study of the pharmaceutical industry? (Control group only) } \\
\hline Yes & - & 367 (60.8) & \\
\hline No & - & $237(39.2)$ & \\
\hline \multicolumn{4}{|l|}{ 17. Would you participate in another drug research study of the pharmaceutical industry? (Case group only) } \\
\hline Yes & $549(90.9)$ & - & \\
\hline No & $7(1.2)$ & - & \\
\hline I do not know & 48 (7.9) & - & \\
\hline
\end{tabular}

Notes: Data were given as $\mathrm{n}(\%)$. aMost common answer. 'Least common answer.

to controls (68.9\%). Correspondingly, less cases $(33.3 \%)$ than controls $(57 \%)$ considered their health was at risk if participating in pharmaceutical clinical trials.

For both groups, the fact that everything is free in clinical trials ranked as the most important motivation to enroll (cases $52 \%$; controls $54.5 \%$ ). Yet, cases (82.3\%) would recommend participating in trials disregarding financial capability to afford medical care more so than controls (59.8\%). Finally, $90.9 \%$ of cases expressed that they would participate in a drug research study again, while only $60.8 \%$ of controls would consider participating in a clinical trial.

\section{Discussion}

Participants' perception about clinical trials can be quite different depending on the severity, prognosis, and available treatment options of their disease. Most studies evaluating perceptions in clinical trials have been carried out in participants with cancer, HIV, and hepatitis C. ${ }^{17-24}$ These patients, frequently nonresponders to standard-of-care medications, are more likely to consider research treatments as an unavoidable alternative, making their perceptions biased and therefore unfit to be generalized to many other diseases. In addition, studies that have included a broad variety of disorders have not analyzed if the participants' diseases have affected their results. ${ }^{10,11,13,16}$ We studied an adult population with one of four common chronic diseases. These diseases all have many available and approved therapeutic choices and a low life-threatening risk in the short-to-medium term. Also, most participants had access to private or social health insurance. Because of this, our findings represent a more accurate evaluation of the reasons and perceptions to participate in clinical trials funded by the pharmaceutical industry.

This multicenter study is the first to be conducted in Mexico exploring the perceptions of volunteer participants of industry-funded clinical trials. Its design allowed us to find that the degree of knowledge that participants have about the process of pharmaceutical clinical research directly influences their final perception, in contrast with the perceptions of nonparticipants with the same disease. Significantly, almost all cases (98.8\%) considered that conducting research studies in humans is "correct" in contrast to just four out of five controls. Nearly one-tenth of controls mentioned the concept of "guinea pigs" when referring to research participants. The majority of cases and controls agreed that the ultimate purposes of clinical research are positive with the main concept being "to cure more diseases and to do so more effectively" and "to find out whether new medications will be more effective and secure". Nevertheless, nearly nine times more controls than cases still believed that the main purpose of clinical research is business or that it is carried out just to "face competition with other companies".

To better understand the meaning of these results, we need to consider that the general public image of the pharmaceutical industry is weak or highly negative almost everywhere..$^{25,26}$ 
There is public concern about the apparent judgment of medications as "nothing more than a consumerist tool", and this idea is naturally extended to the clinical research funded by the pharmaceutical industry. ${ }^{27,28}$ Patients' perception improves if individuals have participated in a clinical trial, as also observed by the Center for Information and Study on Clinical Research Participation. ${ }^{16}$ Significantly, in our report, nearly $95 \%$ of the cases clearly identified the benefits of their participation in the trial. In contrast, ten times more controls than cases believed that clinical trials granted none or minimal benefits to participants. Supporting these results, we found that $90.9 \%$ of cases would participate in another study, given the opportunity. Kost et al also found that $97 \%$ of the population surveyed would recommend research participation to family or friends. ${ }^{13}$ In our study, almost all cases $(99.2 \%)$ would invite another person to participate in a clinical trial, in contrast to $77.5 \%$ of the controls. Furthermore, $>80 \%$ of the cases would recommend participating in a clinical trial to anyone, irrespective of whether they could afford to pay for the treatment themselves, compared to only $59.8 \%$ in the control group, which is a significant difference. These findings reveal that participants perceive that pharmaceutical research offers a high-value medical treatment, regardless of the economic status of the individual.

Meropol et al reported that although oncology patients and physicians are aware of the trials' benefits, three psychosocial barriers impact participation such as: random assignment, fear of receiving placebo, and fear of side effects. ${ }^{29}$ In our study, significantly more cases $(93.4 \%)$ than controls $(68.9 \%)$ felt protected in case of an adverse event, mainly because they trusted the investigator and because they were "aware that the company takes responsibility and takes care of everything". Almost one-third of the controls, however, had the perception that study participants are not protected and half of them believed that "in case a problem arises, no one will defend the patient properly". In addition, significantly more controls (57\%) than cases $(33.3 \%)$ considered that in research projects the participant's health is endangered; however, cases believed that the patients' main reason to participate anyway is "because the health risks are minimal and if there was any problem, the physician would detect it on time".

Participants who considered that their health was not at risk when entering a clinical trial (cases 66.7\% vs controls $43 \%$ ) did so because they believed that the patients are under close and permanent physician surveillance (cases $52.9 \%$ vs controls $50.4 \%$ ) and because "I know there is a committee that makes sure that participants get more benefits than risks for their health. I trust them". Campbell et $\mathrm{al}^{30}$ reported how the negative reputation of research in human participants may impact study enrollment. This negative factor conveys the lack of understanding from the public about the methods and purposes of clinical research and the regulatory and ethical safeguards that the research process has nowadays to protect participants. The work invested on protecting the participants, frequently performed by professional researchers, by certified ethical committees, and by academic institutions, is generally unknown to the public; these evidences, in contrast to pharmaceutical industryrelated negative events, are scarcely publicized. ${ }^{3}$ Therefore, it is necessary to provide potential research participants with adequate information. ${ }^{31}$ Furthermore, regulatory agencies in all countries must approve and certify that clinical research is carried out in professional research sites with committed and certified ethical committees, in order to guarantee that all issues that may arise during the execution of a clinical trial are properly handled. It is worthy to mention that the results of this study are in accordance with other reports from academic institutions also staffed with professional researchers. ${ }^{10-13}$ It would prove useful to test our survey on research sites with inadequately trained personnel participating as collaborators of clinical trials, participants with other diseases, and multinational collaborative studies.

Similarly to our findings, Llewellyn-Thomas et al showed that patients who choose to enter a clinical trial differ substantially from those who choose not to. ${ }^{32}$ As described earlier, almost in every item, we found significant differences between the perception of cases and controls. However, both groups of our study coincide in the notion that the most important motivation to participate in a study is because everything is free of charge. In Mexico, as a developing country, the cost of medical care should be considered as an important factor in the final decision to participate in a pharmaceutical trial. Despite the fact that $>75 \%$ of the participants had access to social or private health insurance, they decided to participate in a clinical trial. As reasonably expected, our findings differ from those found in developed countries where "to help others" (64\%) and "concern about the topic" (56\%) were considered "very important" reasons to participate in a research study, and answers such as "to earn money" and "to obtain free health care" were less frequent. ${ }^{13}$ As recently reported by Ipsos Global Reputation Centre, negative perception about the pharmaceutical industry is worse in industrialized countries than it is in emerging markets, and interestingly Mexico is one of the countries where the industry is viewed less unfavorably. ${ }^{33}$ We further support this concept because $96 \%-99 \%$ of the participants 
in our study recognized the benefits that Mexico has by participating in pharmaceutical industry research. This information could help us have a better perspective of our results, when compared to experiences documented elsewhere. As Nathan recommended, our study shows how important it is to promote the recognized benefits of industry-funded biomedical research among the general public, considering that the lack of knowledge is producing a potential loss of confidence in this activity and is currently threatening the final purpose of clinical research. ${ }^{34}$

\section{Conclusion}

Our multicenter study, in a developing country, in a large population of participants and nonparticipants of pharmaceutical clinical trials, most with access to health insurance and with one of four chronic and highly prevalent disorders with many available and approved treatments, could indicate that clinical trial participation has a positive influence on the perception of pharmaceutical industry-funded clinical research. Participants become aware of the benefits they obtain by enrolling in clinical trials and the rewards of conducting them for the whole country. They also may acquire a sense of security by perceiving that the site staff is capable of handling adverse events, view their current and future participation in clinical trials as a benefit to their health rather than a risk, and would recommend enrollment to others, regardless of their financial status. However, "free of charge medical attention" and "an option for people without health insurance" are strongly prevalent reasons for participation. All this information needs to be conveyed to clinicians, public health authorities, and the general population to overcome misconceptions. Still more information is needed regarding the evaluation of participants' perception in other issues that must be included in high-quality clinical research besides the measurement of the good clinical practice standards during clinical trial execution. Issues such as participant satisfaction, beneficence, value of participation, empathy, and participant information regarding their participation in the trial still need to be thoroughly analyzed.

\section{Acknowledgments}

We wish to thank Carlos Abud-Mendoza, MD; Moises Acuña-Kaldman, MD; Marco Antonio Alcocer-Gamba, MD; Rosario Arechavaleta-Granell, MD; Hilario AvilaArmengol, MD; Manuel Odin de los Ríos-Ibarra, MD; Javier Díaz-Castañon, MD; Guillermo Gonzalez-Galvez, MD; Marco Antonio Loustaunau-Andrade, MD; Leobardo Sauque-Reyna, MD; Jesus Abraham Simon-Campos, MD;
Sergio Lozano-Rodriguez, MD; and Hector Eloy TamezPerez, MD, PhD for their collaboration in the study.

\section{Disclosure}

The authors report no conflicts of interest in this work.

\section{References}

1. Richter TA. Clinical research: a globalized network. PLoS One. 2014; 9(12):e115063.

2. George M, Selvarajan S, SK S, Dkhar S, Chandrasekaran A. Globalization of clinical trials - where are we heading? Curr Clin Pharmacol.2013; 8(2):115-123.

3. Glickman SW, McHutchinson JG, Peterson ED, et al. Ethical and scientific implications of the globalization of clinical research. $N$ Engl J Med. 2009;360(8):816-823.

4. ClinicalTrials.gov. [webpage on the Internet]. Trends, Charts, and Maps. 2016. [cited May 31, 2015]. Available from: https://clinicaltrials. gov/ct2/resources/trends. Accessed May 31, 2015.

5. World Medical Association. World Medical Association Declaration of Helsinki: ethical principles for medical research involving human subjects. JAMA. 2013;310(20):2191-2194.

6. Fischer BA. A summary of important documents in the field of research ethics. Schizophr Bull. 2006;32(1):69-80.

7. Shah S. Globalization of clinical research by the pharmaceutical industry. Int J Health Serv. 2003;33(1):29-36.

8. Rowe M. Making the business case for accreditation. Centerwatch Mon. 2008;15(12):14-17.

9. Cox SM, McDonald M. Ethics is for human subjects too: participant perspectives on responsibility in health research. Soc Sci Med. 2013; 98:224-231.

10. Kost RG, Lee LM, Yessis J, Coller BS, Henderson DK. Assessing research participant's perception of their clinical research experiences. Clin Transl Sci. 2011;4(6):403-413.

11. Yessis JL, Kost RG, Lee LM, Coller BS, Henderson DK. Development of a research participants' perception survey to improve clinical research. Clin Transl Sci. 2012;5(6):452-460.

12. Kost RG, Lee LM, Yessis J, Wesley RA, Henderson DK, Coller BS. Assessing participant-centered outcomes to improve clinical research. N Engl J Med. 2013;369(23):2179-2181.

13. Kost RG, Lee LN, Yessis JL, et al. Research participant-centered outcomes at NIH-supported clinical research centers. Clin Transl Sci. 2014;7(6):430-440.

14. Fleurence R, Selby JV, Odom-Walker K, et al. How the patient-centered outcomes research institute is engaging patients and others in shaping its research agenda. Health Aff (Millwood). 2013;32(2):393-400.

15. Gabriel SE, Normand SL. Getting the methods right - the foundation of patient-centered outcomes research. $N$ Engl J Med. 2012;367(9): 787-790.

16. CISCRP. Report on Study Participant Experiences, 2013 Perceptions \& Insights Study. 2013. Available from: https://www. ciscrp.org/download/2015-perceptions-insights-study-participantexperiences/?wpdmdl=5742. Accessed May 31, 2015.

17. Wu E, Wang T, Lin T, et al. A comparative study of patients' attitudes toward clinical research in the United States and urban and rural China. Clin Transl Sci. 2015;8(2):123-131.

18. Madsen SM, Mirza MR, Holm S, Hilsted KL, Kampmann K, Riis P. Attitudes towards clinical research amongst participants and nonparticipants. J Intern Med. 2002;251(2):156-168.

19. Madsen SM, Holm S, Riis P. Attitudes towards clinical research among cancer trial participants and non-participants: an interview study using a Grounded Theory approach. J Med Ethics. 2007;33(4):234-240.

20. Wright JR, Whelan TJ, Schiff S, et al. Why cancer patients enter randomized clinical trials: exploring the factors that influence their decision. J Clin Oncol. 2004;22(21):4312-4318. 
21. Thorne S, Taylor K, Stephens JML, Kim-Sing C, Hislop TG. Of Guinea pigs and gratitude: the difficult discourse of clinical trials from the cancer patient perspective. Eur J Cancer Care (Engl). 2013;22(5):663-672.

22. Lee SJ, Park LC, Lee J, et al. Unique perception of clinical trials by Korean cancer patients. BMC Cancer. 2012;12:594.

23. Zúñiga ML, Blanco E, Martínez P, Strathdee SA, Gifford AL. Perceptions of barriers and facilitators to participation in clinical trials in HIV-positive Latinas: a pilot study. J Womens Health (Larchmt). 2007; 16(9):1322-1330.

24. Wolak C, Bass SB, Tedaldi E, Vandenburg-Wolf M, Rohrer C. Minority HIV patients' perceptions of barriers and facilitators to participation in clinical research. Curr HIV Res. 2012;10(4):348-355.

25. Pharmaceutical Business Review [webpage on the Internet]. Public perception of US pharmaceutical industry at all-time low. Public Citizen's Commercial Alert [serial on the Internet]; 2005 [cited May 31,2015]. Available from: http://www.commercialalert.org/news/ archive/2005/10/public-perception-of-us-pharmaceutical-industry-atall-time-low. Accessed May 31, 2015.

26. Olsen AK, Whalen MD. Public perceptions of the pharmaceutical industry and drug safety: implications for the pharmacovigilance professional and the culture of safety. Drug Saf. 2009;32(10):805-810.

27. Skripka-Serry $J$ [webpage on the Internet]. Why the pharma industry no longer warrants public trust: reasons for extortionate big pharma drug prices, and what governments are doing to contain them. Bioassociative Innovative Consulting, Industry Blog [serial on Internet]; 2012 [cited May 31, 2015]. Available from: http://bio-associate.blogspot. mx/2012/10/the-pharma-industry-and-public-trust.html. Accessed May 31, 2015.
28. Rehman $\mathrm{J}$ [webpage on the Internet]. Can the source of funding for medical research affect the results? SCIENTIFIC AMERICAN Blogs, a Division of Nature America, Inc [serial on the Internet]; 2012 [cited May 31, 2015]. Available from: http://blogs.scientificamerican. com/guest-blog/2012/09/23/can-the-source-of-funding-for-medicalresearch-affect-the-results/. Accessed May 31, 2015.

29. Meropol NJ, Buzaglo JS, Millard J, et al. Barriers to clinical trial participation as perceived by oncologists and patients. J Natl Compr Canc Netw. 2007;5(8):655-664.

30. Campbell HM, Raisch DW, Sather MR, Segal AR, Warren SR, Naik R. Impact of a clinical trials information handbook on patient knowledge, perceptions, and likelihood of participation. IRB. 2008;30(1):6-14.

31. Leiter A, Diefenbach MA, Doucette J, Oh WK, Galasky MD. Clinical trial awareness: changes over time and sociodemographic disparities. Clin Trials. 2015;12(3):215-223.

32. Llewellyn-Thomas HA, McGreal MJ, Thiel EC, Fine S, Erlichman C. Patients' willingness to enter clinical trials: measuring the association with perceived benefit and preference for decision participation. Soc Sci Med. 1991;32(1):35-42.

33. Ipsos Global Reputation Centre. Reputation Snapshot for the Pharmaceutical Sector. Paris, France: Ipsos Public Affairs; 2012.

34. Nathan DG. Clinical research: perceptions, reality, and proposed solutions. National Institutes of Health Director's Panel on Clinical Research. JAMA. 1998;280(16):1427-1431.
Patient Preference and Adherence

\section{Publish your work in this journal}

Patient Preference and Adherence is an international, peer-reviewed, open access journal that focuses on the growing importance of patient preference and adherence throughout the therapeutic continuum. Patient satisfaction, acceptability, quality of life, compliance, persistence and their role in developing new therapeutic modalities and compounds to optimize

\section{Dovepress}

clinical outcomes for existing disease states are major areas of interest for the journal. This journal has been accepted for indexing on PubMed Central. The manuscript management system is completely online and includes a very quick and fair peer-review system, which is all easy to use. Visit http://www. dovepress.com/testimonials.php to read real quotes from published authors. 